\title{
Historia de Mayta: el narrador comprometido
}

\section{Historia de Mayta: the committed narrator}

\section{Luis Ángel del Castillo Saldaña'}

Saint Matthew's College North. Buenos Aires, Argentina

Idelcastillo@smcn.edu.ar

ORCID 0000-0002-3510-1106

Citar como: Del Castillo, L. (2020). Historia de Mayta: el narrador comprometido. Desde el Sur, 12(1), pp. 13-21.

\section{RESUMEN}

A través de sus primeras novelas, Vargas Llosa proponía, desde una perspectiva socialista, el poder de la literatura para contribuir al cambio social, pero con Historia de Mayta ya no mantiene el aura colectivista de antaño, de cambiar de a pocos o indirectamente la vida de las personas en pro de una vida más justa y equitativa; sino que ahora es más individual. Desde esta perspectiva, el narrador-investigador de la novela es un reflejo explícito y panfletario del cambio ideológico de Vargas Llosa, de su praxis novelística y su nueva concepción de la literatura, que serán una orientación acorde y en sintonía con su nueva postura liberal.

\section{PALABRAS CLAVE}

Mario Vargas Llosa, narrador comprometido, liberalismo

\section{ABSTRACT}

Through his earliest novels, from a socialist perspective Vargas Llosa addressed the power of literature to contribute to social change, but with the novel Historia de Mayta he no longer espouses the collectivist ideal of yesteryear, the gradual or indirect changing of people's lives towards a more just and equitable existence. Instead, his approach is more individualistic. The narrator-researcher of the novel represents an explicit and highly-colored reflection

1 Magíster de la Universidad de Buenos Aires en Literaturas Española y Latinoamericana, y bachiller en Literatura de la Universidad Nacional Mayor de Marcos. 
upon the ideological change undergone by Vargas Llosa, upon his work as a novelist, and upon his new approach to literature, in accordance with his new liberal position.

\section{KEYWORDS}

Mario Vargas Llosa, committed narrator, liberalism

\section{Introducción}

Mario Vargas Llosa, en un artículo de 1964 («Los otros contra Sartre», 1984), manifiesta que el escritor no solo tiene un compromiso lícito con el lenguaje, sino también con la sociedad; a la vez, afirma que la creación literaria tiene raíces sociales. Es decir, el escritor auténtico escribe para una clase social determinada.

Esta concepción ideológica también la lleva a la literatura. Prueba de ello son sus primeras obras ficcionales y ensayísticas, donde plasma sus concepciones sobre la novela: la totalidad, el compromiso y la autonomía de la novela, por mencionar los aspectos más importantes. Al respecto, David Sobrevilla expresa que en la primera teoría de la novela de Vargas Llosa se manifiesta el concepto de libertad sartreana, la postura de la novela como totalidad y la autonomía de la novela que proviene de Flaubert. Pero estas concepciones cambian a mediados de la década de 1970, cuando abandona la idea de la novela como totalidad. Si antes la novela debía representar verbalmente la realidad en todos sus niveles y abarcar toda la realidad, ahora solo apunta a su autonomía: «la novela ya no representa más la realidad, sino que la distorsiona a partir de las obsesiones y creencias personales del novelista» (Sobrevilla, 1991, p. 64). Otro aspecto, para Sobrevilla, radica en la concepción del arte en general y, específicamente, de la novela como una «mentira verdadera». Finalmente, un tercer elemento es que renuncia a «los consejos flaubertianos de la impersonalidad, imparcialidad e impasibilidad al momento de escribir» (Sobrevilla, 1991, p. 68).

Las primeras tres novelas de Vargas Llosa, La ciudad y los perros (1963), La casa verde (1966) y Conversación en La Catedral² (1969), se circunscriben en la primera teoría de la novela del autor peruano. Pero con la publicación de las novelas Pantaleón y las visitadoras (1973), La tía Julia y el escribidor (1977), La guerra del fin del mundo (1981) e Historia de Mayta (1984),

2 En esta novela, si analizamos la dicotomía contenido-forma, percibimos que en su aspecto formal o técnico Vargas Llosa mantiene su postura de la primera teoría de la novela, pero en su aspecto conceptual notamos algunos rasgos, sobre todo de su postura política y social, que corresponden a la segunda. 
a la vez que cambia su postura ideológica, cambia su praxis novelística ${ }^{3}$. Particularmente, queremos detenernos en esta última novela para analizar al narrador-escritor, y ver cómo presenta su mundo autónomo, suponiendo que la historia que está investigando llega a publicarse y es la que nos presenta.

\section{El narrador-escritor}

En Historia de Mayta se narra el conato revolucionario de Mayta en 1958, en la ciudad de Jauja, en la sierra peruana. La historia nos llega a través de un narrador-escritor, cuya enunciación ocurre en 1983, 25 años después de los sucesos.

La novela inicia con la descripción de la ciudad de Lima, en un símil con la sociedad en la que se encuentra el narrador-escritor en el momento de la enunciación: todo es podredumbre, los muladares invaden los espacios de la ciudad desde los barrios marginales hasta los residenciales y exclusivos. Pero la sociedad se muestra impávida frente a esta situación, como si fuera algo que tiene que sufrir o como un castigo ineluctable. Esta escena es parte de la historia peruana que vive en ese momento el narradorescritor, donde las fuerzas de antaño no se vislumbran por ningún rincón de las calles limeñas, y tampoco por ningún resquicio de la sensibilidad y el raciocinio de los hombres: «Por eso se han resignado a los gallinazos, las cucarachas, los ratones y la hediondez de estos basurales que he visto nacer, crecer, mientras corría en las mañanas» (Vargas Llosa, 1985, p. 8). Desde el inicio la narración surge «como punto de partida concientizador. La visión de una Lima desolada, fea, asfixiada de rejas con que comienza la novela, alerta al lector sobre la historia que leerá» (Salem, 1996, p. 177). El inicio desamparado y lúgubre de la ciudad se presenta como una prolepsis del destino del protagonista, en particular, y de la sociedad en general.

Pero Mayta, el protagonista, nunca se habituó a los muladares, que eran exclusivos de los barrios marginales en 1958, año en el que actúa para revertir la situación antes de que la desidia y la pobreza material y espiritual invadieran la existencia plena. Sin embargo, todo indica que el intento de Mayta de enmendar la situación fracasó, porque el narradorescritor nos adelanta el resultado de las acciones del protagonista, cuando dice que «el remedio fue peor que la enfermedad».

3 Varios críticos han señalado que con La guerra del fin del mundo (1981) regresa a sus postulados teóricos de la novela de su primera etapa. Sin embargo, Cornejo Polar vislumbra la tesis de esta novela que se presentará más explícita en Historia de Mayta: «Los errores de uno y otro son, en el fondo, los mismos y derivan de una misma fuente: el fanatismo que ciega a los hombres» (1989, p. 240). En Historia de Mayta el fanatismo ciego solo será de los revolucionarios y sus consecuencias nefastas en el Perú actual. 
El narrador-escritor presenta la historia de Alejandro Mayta a través de entrevistas, averiguaciones, investigaciones en bibliotecas y hemerotecas. Reconstruye el intento revolucionario — de su condiscípulo salesianode 1958 en la sierra de Jauja, tentativa que será la semilla de la violencia político-social que devendrá en el cataclismo del presente del relato. Pero la posición del narrador-escritor para presentar los acontecimientos políticos y sociales —en el momento de la enunciación- está en la perspectiva de los intelectuales que habían abandonado su posición marxista y revolucionaria hacia posiciones más cómodas con la profesión y la «ahora invocada lucha contra el «estatismo» se haría en nombre de una «quimera sociedad civil» (Mansilla, 2003, p. 33) . La valoración dicotómica y maniqueísta del narrador-escritor en toda la novela «constituye un proyecto claramente inscrito en una filiación política y abierta a una interpretación crítica de su tiempo» (Salem, 1996, p. 184). Para el narrador-escritor el Perú catastrófico del presente es efecto y no causa de esa revolución frustrada, de algunos individuos enloquecidos y no de la injusticia del sistema social imperante (Cornejo Polar, 1989, p. 250).

Algunos críticos han señalado que el narrador-escritor de Historia de Mayta se deja influenciar por el Vargas Llosa real, y que «tal referencialidad inmediata es parte importante de la estrategia del discurso como resultado, la irracionalidad invade la hipótesis apriorística de la conflictividad social, y el liberalismo autoritario controla la escritura» (Rowe, 1990, p. 91). Esta argumentación es pertinente si tenemos en cuenta que para Vargas Llosa «la guerra entre ambos órdenes [explotados-explotadores] es a muerte y no hay manera de ser neutral ni indiferente» (1984, p. 13). Además, siguiendo esta perspectiva, el narrador-escritor tiene una posición ideológica discrepante de Mayta — coincidiendo con el autor real-, y considera que la novela es una crítica social. En consecuencia, debe escribir lo que está investigando, antes que se deje ganar por la desesperación, porque, «por efímera que sea, una novela es algo, en tanto que la desesperación no es nada» (Vargas Llosa, 1985, p. 91).

Birger Angvik señala — contradiciendo a la crítica en general ${ }^{5}$, porque leyó esta novela como a las primeras novelas de Vargas Llosa, donde predomina la crítica de la realidad-, que Historia de Mayta debe ser leída en

4 Para Salem, «en las elipsis narrativas y en los silencios de lo no dicho, lo impronunciable, hay un testimonio que da cuenta del lugar ideológico en que está instalado el autor» (1996, p. 183). Birger Angvik también ha señalado la posición ideológica del narrador-escritor desde el inicio de la novela: «Hacer de Lima un gran basural, y hacer del Museo de la Inquisición un símbolo totalizador de la realidad peruana, son exageraciones reduccionistas que caracterizan a este "yo" como personaje literario» (1989a, p. 115).

5 Entre ellos a Antonio Cornejo Polar, Susana Reisz de Rivarola, Edgar O’Hara y Ricardo González Vigil (1989b). 
el mismo derrotero «como se leen Los cachorros, Pantaleón y las visitadoras y La tía Julia y el escribidor: como novelas en las que el realismo defendido se deja mezclar con grandes dosis de procedimientos melodramáticos y cómicos» (Angvik, 2004, p. 219). En su análisis, Angvik interpreta la autoparodia del escritor-narrador, que busca «la novela total» y «la novela autónoma» - aunque sustente que este último elemento es el logro de la novela-, que fueron postulados metodológicos de las tres primeras novelas del autor real. Es así que este narrador-escritor se muestra fanático y dogmático, porque está siendo víctima de las propias distorsiones como nos presenta la ciudad y la sociedad peruanas. De igual modo, es la insistente y reiterativa afirmación de que está investigando para escribir una novela, pero que investiga para «mentir con conocimiento de causa» ${ }^{6}$. Otro aspecto para su hipótesis es que parodia la novela testimonial, porque cree que todos los entrevistados mienten y, en general, todos los peruanos, porque viven una ficción, hasta ponerse en duda él mismo, considerando que es peruano. Finalmente, se presenta la parodia de la novela del guerrillero, que presenta a Mayta como un antihéroe. El protagonista es cegado por su idealismo teórico, al igual que el narrador se equivoca en su metodología de trabajo sobre el arte de escribir novelas. En consecuencia, «Mayta y el escritor-narrador comparten el hecho de ser, en diferentes campos de actividad, dos personajes de proyectos que fracasan» (Angvik, 2004, p. 238). Sin embargo, Angvik reconoce que:

Con la ridiculización del escritor-narrador, quien ridiculiza a su vez a Mayta, a toda la izquierda política en el Perú y sus gustos estéticos y literarios, la novela representa un tipo de novela satírica, comprometida e inusitada en la historia de la literatura peruana: la novela comprometida con la política conservadora (Angvik, 2004, p. 239).

Compartimos las propuestas de Angvik, pero consideramos que la representación principal y esencial que se hace en la novela es la ridiculización del protagonista y la proyección paródica de la izquierda peruana y latinoamericana. Para ello, utiliza los prejuicios de esta sociedad respecto a las características de la personalidad del protagonista, que se contrasta con la intención dicotómica entre lo hegemónico y lo marginal. Somos conscientes del uso de la parodia y lo grotesco, pero estos recursos

6 Esta insistencia del narrador-escritor al repetir que investiga para «mentir con conocimiento de causa» y que está escribiendo una novela, por lo tanto ficcional, es cuestionada por Cornejo Polar, porque el carácter ficcional de la novela es una obviedad, pero la realidad que describe es una realidad histórica que no es ficcional. Vinculada a esta idea, está la concepción de «Las mentiras verdaderas» de Vargas Llosa, que utiliza «como título de su prólogo de La señorita de Tacna (1981). En este prólogo define lo que representa la ficción en la vida del hombre, que él recurre a ella para sobrellevar la vida. Porque "La ficción es el hombre 'completo', en su verdad y en su mentira confundidas"» (Del Castillo, 2013, p. 123). 
narrativos solo sirven como instrumento de desacralización de la concepción ideológica del protagonista y de la izquierda peruana; porque no fueron bien trabajados - en Pantaleón y las visitadoras se mofa de todo y todos $^{7}$ - , en Historia de Mayta, ya que no llega con la misma intensidad a todos los integrantes del mundo creado, porque parcializa y tergiversa la complejidad del protagonista y la ideología que profesa. Alejandro Mayta no tiene forma de escapar a la mirada autoritaria del escritor-narrador; su punto de vista tiende a apelar a los prejuicios de los potenciales lectores al mismo nivel que manifiestan sus prejuicios los personajes que conocieron a Mayta dentro de la ficción, creando el ambiente propicio para la «autonomía de la novela».

La perspectiva autoritaria del narrador-escritor se podría sintetizar cuando describe la vida de Mayta de un plumazo a través de una fotografía: la frustración y la marginalidad se notan no solo en la presencia del protagonista que refleja la imagen, sino hasta en el mismo objeto físico que sirve para representarlo. Sin embargo, podríamos inferir que el narrador-escritor hace concesiones a la buena imagen de Mayta, a través de la exageración, pero con la finalidad de ridiculizar su idealismo. Y como producto de la imagen positiva-compasiva que tiene la gente que reniega del legado andino, tiende a atribuir al indio virtudes de humildad, honradez y buenas intenciones, pero siempre manteniéndolo lejos como un paria. En consecuencia, a simple vista la lucha de Mayta por cambiar las injusticias del Perú no fue un destello de irresponsable emoción, sino de un convencimiento de principios. Sin embargo, esta imagen de un hombre convencido se pierde en el transcurso de la novela, porque la lucha y la ideología del protagonista caen en el fanatismo que conlleva a un final patético. La presentación de Mayta con bellos ideales se diluye, ya que es llevado a la exageración y el ridículo. Elogia al protagonista hasta la cumbre de sus ideales, a la cima, pero para que la caída, al final de la novela, sea más estrepitosa y ruidosa ${ }^{8}$. El final de Mayta acentúa no solo su marginalidad, sino su ideología errónea, alucinada y ridícula. Tal es la intención del narrador-escritor ${ }^{9}$, quien pretende generar un tipo de conciencia propia

7 En esta novela se presenta la ridiculización de la existencia plena del mundo ficcionalizado: las autoridades militares, el periodismo radial y escrito, el ambiente femenino y masculino, las culturas populares y sus creencias, etc. (Richards, 1986).

8 A ello debemos agregar la orientación sexual del protagonista, porque «las atribuciones de homosexualidad y represión psíquica pretenden explicar la política pervertida de Mayta» (Rowe, 1990, p. 92).

9 También se presentan las consecuencias sociales e individuales del intento revolucionario de Mayta en el presente en contraste con el pasado. La decadencia actual está impregnada hasta en las acciones más cotidianas de la existencia, o en las celebraciones más transcendentales del ser humano, como el festejo social del cumpleaños de doña Josefa, tía de Mayta. En la época antes del intento revolucionario de Mayta, doña Josefa celebra su cumpleaños 
del pensamiento liberal: las consecuencias catastróficas del Perú del relato es efecto de la revolución iniciada por unos fanáticos e irresponsables y no por las causas de la injusticia social (Cornejo Polar, 1989, p. 254). Así, esta ficción de Vargas Llosa manifiesta «su posición política e ideológica conservadoras que se reflejan a través de la complacencia frente al estado actual de las cosas (Del Castillo, 2013, p. 119). A provecha el abordaje literario para responder a la izquierda y criticar el socialismo (como si estuviese continuando el debate de la década de 1970, cuando empieza a cambiar su posición política), con referencias políticas muy claras que antes no se apreciaban tan directamente en sus novelas.

\section{Conclusión}

En Historia de Mayta el narrador-escritor nos presenta a sus personajes en «la excrecencia de una subcultura. Es la cultura de la pobreza y aun de la podredumbre» (Oviedo, 1982, p. 277). El narrador-escritor crea un mundillo donde los prejuicios sociales son las manifestaciones hegemónicas y normalizadas de esta sociedad, pero a la vez apela a un potencial lector «complaciente» con su «novela autónoma», hasta hacer de su ficción un chiste tendencioso cargado de agresividad y hostilidad (Angvik, 2004, p. 223), y dirigido a un auditorio que retoza con la sandez, cuyo narrador quiere encontrar afinidad y defensa ideológica: el liberalismo.

A través de sus primeras novelas, Vargas Llosa proponía el poder de la literatura para contribuir al cambio social, pero con Historia de Mayta ya no mantiene el aura colectivista de antaño, de cambiar de a pocos o indirectamente la vida de las personas en pro de una vida más justa y equitativa; ya no se proyecta hacia el futuro de la humanidad, sino que ahora es más individual. Desde esta perspectiva, esta novela es un reflejo explícito y panfletario de su cambio ideológico, de su praxis novelística y su nueva concepción de la literatura que se convirtió en su orientación acorde y en sintonía con su nueva postura ideológica.

como un acontecimiento del barrio, como si fuera la celebración de la independencia. Sin embargo, en el momento en que el narrador-escritor la entrevista, doña Josefa no celebra su cumpleaños, la pasa en soledad en compañía de la televisión para posteriormente ir a acostarse. Asimismo, este Perú de cataclismo fue invadido por fuerzas extranjeras - los estadounidenses - para luchar contra la subversión. 


\section{Contribución del autor}

Luis Ángel del Castillo Saldaña ha participado en la concepción, la recolección de datos, la redacción y la aprobación de la versión final del artículo.

\section{Fuente de financiamiento}

Autofinanciado.

\section{Conflicto de interés}

El autor declara no tener conflictos de interés.

\section{REFERENCIAS BIBLIOGRÁFICAS}

Angvik, B. (1989a). La teoría de la novela de Mario Vargas Llosa y su aplicación en la crítica literaria: desde la indeterminación metafórica del lenguaje a la sobredeterminación categórica del lenguaje crítico. Hueso Húmero, 25, pp. 26-58.

Angvik, B. (1989b). Historia de Mayta: la novela y los críticos. Hueso Húmero, 25, pp. 111-119.

Angvik, B. (2004). La narración como exorcismo. Mario Vargas Llosa, obras (1963-2003). Lima: Fondo de Cultura Económica.

Cornejo Polar, A. (1989). La historia como Apocalipsis (sobre Historia de Mayta de Vargas Llosa). En La novela peruana (pp. 243-256). Lima: Horizonte. 
Cornejo Polar, A. (1989). La guerra del fin del mundo: sentido (y sin sentido) de la historia. En: La novela peruana (pp. 231-242). Lima: Horizonte.

Del Castillo, L. (2013). La construcción de la imagen del intelectual liberal». En Miríada doxológica. La autofiguración de Mario Vargas Llosa en sus ensayos y autobiografía. Recuperado de https://www. academia.edu/38227669/Tesis._Mir\%C3\%ADada_doxol\%C3\%B3gica. La_autofiguraci\%C3\%B3n_de_Mario_Vargas_Llosa_en_sus_ensayos_y_ su_autobiograf\%C3\%ADa.doc

Mansilla, H. C. F. (2003). Intelectuales y política en América Latina. En W. Hofmeister y H. C. F. Mansilla (Eds.), Intelectuales y política en América Latina. Buenos Aires: Homo Sapiens.

Oviedo, J. M. (1970). Mario Vargas Llosa: la invención de una realidad. Barcelona: Seix Barral.

Richards, T. (1986). Pantaleón y las visitadoras: lo grotesco festivo. Texto Crítico, 34-35, pp. 243-250.

Rowe, W. (1990). Liberalismo y poder: una lectura política de Vargas Llosa. Hueso Húmero, 26, pp. 79-94.

Salem, D. B. (1996). Historia de Mayta de Mario Vargas Llosa. Semántica de una ficción ideológica. En M. Domínguez (Coord.), Historia, ficción y metaficción en la novela latinoamericana contemporánea. Buenos Aires: Corregidor.

Sobrevilla, D. (1991) La nueva teoría de la novela de Mario Vargas Llosa. Cuadernos Hispanoamericanos, 496, pp. 59-72.

Vargas Llosa, M. (1983). Contra viento y marea (1962-1982). Buenos Aires: Sudamericana.

Vargas Llosa, M. (1984). Historia de Mayta. Buenos Aires: Sudamericana. 